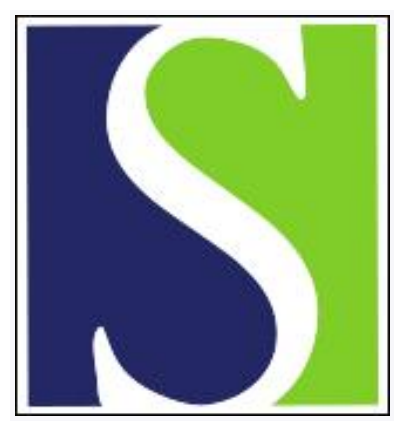

Scand J Work Environ Health 1979;5(3):271-279

https://doi.org/10.5271/sjweh.3101

Issue date: Sep 1979

Temperature changes in contact lenses in connection with radiation from welding arcs

by Lövsund P, Nilsson SEG, Lindh H, Öberg PA

Affiliation: Department of Ophthalmology, University Hospital, University of Link6ping, S-581 85 Linköping, Sweden.

Refers to the following texts of the Journal: 1979;5(3):280-285

$1979 ; 5(3): 262-270$

The following articles refer to this text: 1979;5(3):262-270;

$1979 ; 5(3): 280-285$

Key terms: contact lense; corneal damage; occupational safety; radiation; radiation hazard; soft contact lense; temperature; temperature change; welding; welding arc; worker safety

This article in PubMed: www.ncbi.nlm.nih.gov/pubmed/20120575

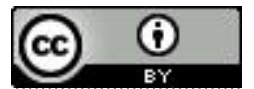




\title{
Temperature changes in contact lenses in connection with radiation from welding ares
}

\author{
by PER LÖVSUND, M.Sc.E.E., ${ }^{1}$ SVEN ERIK G. NILSSON, M.D., Ph.D., ${ }^{2}$ \\ HANS LINDH, O.O., ${ }^{2}$ and P. ÅKE ÖBERG, Ph.D. ${ }^{1}$
}

\begin{abstract}
LÖVSUND, P., NILSSON, S. E. G., LINDH, H. and ÖBERG, P. A. Temperature changes in contact lenses in connection with radiation from welding arcs. Scand. $j$. work environ. \& health 5 (1979) 271-279. Because of reports of risks associated with the use of contact lenses during exposure to welding arcs, the temperature changes in soft contact lenses were recorded in connection with certain types of welding [manual metal arc (MMA) welding, tungsten inert-gas (TIG) welding, and metal inert-gas (MIG) welding], both with free-hanging lenses and lenses applied to the eyes of anesthetized rabbits. A great increase in temperature was noted, especially with MMA welding. At a distance of $0.4 \mathrm{~m}$ the temperature of a lens on a rabbit eye rose from about 35 to $50^{\circ} \mathrm{C}$ within $6 \mathrm{~min}$, whereas the air temperature only increased from 23 to $30^{\circ} \mathrm{C}$. The increase was the greatest at the beginning of the welding period. Most of the lenses completely dried out during the experiment, and there would seem to be a potential risk that the lens would adhere to the cornea. One safety glass screen (DIN $10 \mathrm{~A}$ ) proved effective in preventing the rise in temperature in contact lenses during MMA welding. Even though it is impossible to direct the eyes at the arc for a prolonged period of time, the use of contact lenses in connection with at least certain types of welding is not to be recommended without the use of a suitable safety glass screen (or safety glasses). With regard to the large number of particles in the welding environment, also a risk factor for contact lens wearers, it is doubtful whether even safety glasses or screens are satisfactory unless they fit closely.
\end{abstract}

Key words: corneal damage, radiation hazards, soft contact lenses, temperature changes, welding arcs, worker safety.

During recent years a number of contradictory reports have appeared on possible hazards associated with the wearing of contact lenses during welding. The original incident, which seems to have taken place

1 Department of Biomedical Engineering, University of Linköping, Sweden.

2 Department of Ophthalmology, University of Linköping, Sweden.

Reprint requests to: Prof. S. E. G. Nilsson, Department of Ophthalmology, University Hospital, University of Linköping, S-581 85 Linköping, Sweden. at the Bethlehem Steel Corporation, U.S.A. (12), has been described in many journals $(8,9)$. It became known in Sweden in 1976 and attracted a great deal of attention. It involved a shipyard worker who was wearing contact lenses behind safety glasses and who was exposed to an arc flash in a breaker $(440 \mathrm{~V})$ when connecting a welding cable. When he later removed his lenses "large areas of dried cornea" came away with them. Apparently only the superficial epithelial layer was affected. The report resulted in the recommendation that contact lenses should not be worn, 
even under safety glasses, in any place where an arc flash may occur. According to a report in The Welding Institute Research Bulletin (8) this recommendation was for a period also adopted by The Royal Society for the Prevention of Accidents (RSPA), England. It later transpired that the contact lenses in the case in question had been worn for a continuous period of $17-18 \mathrm{~h}$, which alone was presumed to be enough to explain the drying of the lenses and separation of the epithelium when the lenses were removed $(8,10,11)$.

Novak and Saul (6) and Fox (1) report apparently the same incident. Novak and Saul maintain, as a principle, that contact lenses are contraindicated in industrial work. Fox is of the opinion that no one working in connection with infrared, ultraviolet, or other radiation energy should be allowed to wear contact lenses at work.

The National Society for the Prevention of Blindness (NSPB) (13) asserts, partly because welding arcs can cause contact lenses to adhere to the cornea, that the wearing of contact lenses in industrial environments without the use of eye and face shields fulfilling all the requirements of the American standard ANSI Z87 should never be allowed.

The question, "Is it dangerous for arc welders to wear contact lenses?" was posed in the British Medical Journal in 1974 (7). The reply was that there is no risk if industrial goggles are worn, provided the welder is an established wearer of contact lenses. Nevertheless, the general advice is given that contact lens wearers should "in practice avoid exposure to atmospheric pollution and arc flash hazards, and, where laboratory and industrial environment cannot be made safe in these respects, then contact lenses should not be worn by employees."

In a recent article in RSPA's journal Occupatioal Safety and Health (12) the incident at Bethlehem Steel is dismissed as an "industrial atrocity story." Dr. Smith of the Employment Medical Advisory Service is quoted as saying that "there is no hazard" to welders from using contact lenses. She claims that the greatest danger is from "overwear," thermal effects of such a degree as to damage the cornea being extremely unlikely. RSPA's Senior Technical Officer, John Hart, concludes that "if a wearer of contact lenses did sustain a flash burn he would have some degree of ultraviolet keratoconjunctivitis, and this might be further irritated by the lens, but in such cases prompt removal of the lenses and application of the normal treatment for arc eye is all that is necessary."

To our surprise we have been unable to find reports of any experimental investigations on this important matter. In the present study the temperature changes that take place in contact lenses in connection with welding were determined. Comparisons are made between different types of lenses and different welding methods. The investigation covers freehanging lenses and lenses applied to the eyes of anesthetized rabbits. In certain cases a considerable rise in temperature was noted. Concurrently with this work we have carried out a study on the transmittance and absorption properties of contact lenses (5), from which it is clear that the absorption is very great, especially in the long-wave region of infrared and the short-wave region of ultraviolet light. In addition infrared heaters were tested for possible effects on contact lenses (4).

\section{MATERIAL AND METHODS}

\section{Temperature recording}

Temperatures were measured with a copper-constantan (T) thermocouple (High Temperature Instruments Corporation, U.S.A.), the tip of which was flattened to a thickness of approximately $80 \mu$. The temperature was read on a five-channel digital temperature indicator (Doric, U.S.A.) with a resolution of $0.1^{\circ} \mathrm{C}$. Linearization and compensation for the cold junction are built into the instrument. Only soft contact lenses of the HEMA (hydroxyethyl methacrylate) type were used in connection with the temperature recording. The thermocouple was placed at the center of the lens with the probe tip within the lens. At the start of each 
recording the lens was wet with physiological saline. Control experiments failed to demonstrate any false temperature increase from the absorption of infrared radiation by the naked thermocouple (4).

\section{Test program}

Comparison between lenses of different manufacturers. In a comparison of different manufacturers' products, the temperature of certain lenses was recorded under radiation from one and the same welding apparatus, namely, the MAG ESAB LDA 275 (electrode $1 \mathrm{~mm}$, shielding gas $20 \%$ carbon dioxide and $80 \%$ argon), current $250 \mathrm{~A} \mathrm{DC}$, iron being used as the welding material. The distance between the lens and arc was $0.3 \mathrm{~m}$. All the lenses examined were HEMA-based soft lenses, as specified in table 1.

Comparison between different welding methods. For the comparison of the possible temperature-raising effects of different welding methods on contact lenses, the ideal approach would be to select methods that have emissions closely corresponding to the absorption of the contact lenses. Since, however, the availability of emission measurements over a sufficiently broad spectrum is very limited, we examined instead three common welding processes, namely, manual metal arc (MMA) welding, tungsten inert-gas (TIG) welding (two methods), and metal inertgas (MIG) welding with an MAG apparatus. In these experiments a contact lens with a centrally applied thermocouple was allowed to hang free, the radiation from the welding process being directed towards the front of the lens. As can be seen from table 2, two comparable lenses were used, both HEMA-based, with a water content of $39 \%$ and a center thickness of about $0.5 \mathrm{~mm}$. A second thermocouple was placed in front of the lens to record the temperature of the immediately surrounding air. Welding was performed by an experienced worker, and the arc could therefore be kept fairly constant throughout the experiment. When an electrode was exhausted it was quickly re-

Table 1. Specifications of the compared contact lenses.

\begin{tabular}{lccc}
\hline Manufac- & Diopter & $\begin{array}{c}\text { Approximate } \\
\text { Water } \\
\text { con- } \\
\text { tent } \\
(0 / 0)\end{array}$ & $\begin{array}{c}\text { thickness of } \\
\text { lenset) at } \\
\text { the site of } \\
\text { the thermo- } \\
\text { couple } \\
\text { (mm) }\end{array}$ \\
\hline Soflens & +17.50 & 39 & 0.5 \\
Hydron & +21.50 & 39 & 0.5 \\
Weicon & +15.00 & 39 & 0.6 \\
Scanlens & +24.00 & 85 & 0.8 \\
Scanlens & -5.50 & 85 & 0.2 \\
\hline
\end{tabular}

Table 2. Experimental conditions used in the comparison between welding methods. (MMA = manual metal arc, TIG = tungsten inert-gas, $\mathrm{MIG}=$ metal inert-gas)

\begin{tabular}{|c|c|c|c|c|}
\hline \multirow[b]{2}{*}{ Variable } & \multicolumn{4}{|c|}{ Welding method } \\
\hline & $\begin{array}{c}\text { MMA, ESAB } \\
\text { KC } 375\end{array}$ & $\begin{array}{c}\text { TIG (1), AGA } \\
\text { DA } 35\end{array}$ & $\begin{array}{c}\text { TIG (2), AGA } \\
\text { DA } 35\end{array}$ & $\begin{array}{c}\text { MIG, MAG, } \\
\text { ESAB } \\
\text { LDA } 275\end{array}$ \\
\hline $\begin{array}{l}\text { Current } \\
\text { Distance between }\end{array}$ & $275 \mathrm{~A} D C$ & $110 \mathrm{~A} \mathrm{AC}$ & 110 A DC & 175 A DC \\
\hline contact lens and arc & $0.3 \mathrm{~m}$ & $0.3 \mathrm{~m}$ & $0.3 \mathrm{~m}$ & $0.3 \mathrm{~m}$ \\
\hline Material & Iron & Aluminum & Iron & Iron \\
\hline Electrode & $\begin{array}{l}4 \mathrm{~mm} \text {, high } \\
\text { efficiency }\end{array}$ & $3.2 \mathrm{~mm}$ & $3.2 \mathrm{~mm}$ & $0.8 \mathrm{~mm}$ \\
\hline Shielding gas & - & Tungsten & Tungsten & $\begin{array}{l}20 \% \text { carbon } \\
\text { dioxide, } 80 \% \\
\text { argon }\end{array}$ \\
\hline $\begin{array}{l}\text { Contact lens } \\
\text { Welding time }\end{array}$ & $\begin{array}{l}\text { Soflens }+17.50 \\
5 \text { min }\end{array}$ & $\begin{array}{l}\text { Soflens }+17.50 \\
5 \text { min }\end{array}$ & $\begin{array}{l}\text { Hydron }+22.50 \\
5 \text { min }\end{array}$ & $\begin{array}{l}\text { Hydron }+22.50 \\
5 \text { min }\end{array}$ \\
\hline
\end{tabular}


placed, and welding proceeded after only a very brief interruption. The experimental conditions are summarized in table 2 .

Measurement of temperature in lenses applied to rabbit eyes. Some cooling should normally result from the irrigation of the lens by tears, and the eyelid and bulb probably also assist in cooling. In order to achieve conditions as close as possible to "natural," we also measured the temperature of lenses applied to rabbit eyes. Adult, pigmented rabbits were anesthetized with intravenous propanidid and pethidine, a method giving anesthesia without closure of the eyes and with apparently unaffected tear secretion.

Under these circumstances it proved difficult to retain the thermocouple in the lens. A double lens, the inner lens of which had radii of curvature equal to those of the cornea and the inner surface of the outer lens, was therefore used. The two lenses were glued together at the extreme periphery. The thermocouple, which had been bent to correspond with the curvature of the lenses, was introduced between the wet lenses, care being taken to avoid air bubbles. Before each exposure the lenses were rewet with physiological saline. A second thermocouple was placed in front of the lens to measure the air temperature. The rabbit was arranged so that the optical axis of the examined eye was directed towards the arc. The three types of lenses tested (HEMA lenses with a $39 \%$ water content) are specified in table 3 .

In the rabbit experiments the IMIMA process (ESAB, KC 375), with a high efficiency 4-mm electrode (OK-FEMAX 3895), a welding current of $240 \mathrm{~A} \mathrm{DC}$, an eyearc distance of $0.4 \mathrm{~mm}$, and a welding time of $6.5 \mathrm{~min}$, was used.

Table 3. Lens combinations used in the rabbit experiments.

\begin{tabular}{ccc}
\hline Lens combination & $\begin{array}{c}\text { Manufacturer and } \\
\text { diopter }\end{array}$ & $\begin{array}{c}\text { Approximate thickness } \\
\text { of wet lens at the site } \\
\text { of the thermocouple }(\mathrm{mm})\end{array}$ \\
\hline 1 & $\begin{array}{l}\text { Hydron }-1.75 \\
\text { Soflens }+3.50 \\
\text { Weicon }+15.50 \\
\text { Weicon }+15.50 \\
\text { Hydron }-1.00 \\
\text { Hydron }-1.50\end{array}$ & 0.6 \\
\hline
\end{tabular}

Table 4. Increase in temperature $\left({ }^{\circ} \mathrm{C}\right)$ in free-hanging, wet contact lenses: A comparison between different lenses.

\begin{tabular}{|c|c|c|c|c|c|}
\hline & \multicolumn{5}{|c|}{ Type of lens } \\
\hline & $\begin{array}{l}\text { Soflens } \\
+17.50\end{array}$ & $\begin{array}{l}\text { Hydron } \\
+21.50\end{array}$ & $\begin{array}{l}\text { Weicon } \\
+15.00\end{array}$ & $\begin{array}{c}\text { Scanlens } \\
+24.00\end{array}$ & $\begin{array}{c}\text { Scanlens } \\
-5.50\end{array}$ \\
\hline \multicolumn{6}{|l|}{ Lens temperature } \\
\hline Initial & 14 & 16 & 17 & 15 & 14 \\
\hline Final & 30 & 29 & 31 & 27 & 24 \\
\hline Increase & 16 & 13 & 14 & 12 & 10 \\
\hline \multicolumn{6}{|l|}{ Air temperature } \\
\hline Initial & 17 & 17 & 18 & 17 & 18 \\
\hline Final & 20 & 21 & 21 & 19 & 20 \\
\hline Increase & 3 & 4 & 3 & 2 & 2 \\
\hline \multicolumn{6}{|l|}{ Difference between } \\
\hline and air temperatures & +10 & +8 & +10 & +8 & +4 \\
\hline
\end{tabular}

